\title{
Antioxidant Potentials of Tomato Paste Extracts Found on Major Markets in Accra Metropolis
}

\author{
Shadrack Donkor ${ }^{1}$, Akwasi Akomeah Agyekum ${ }^{1}$, Felicia Akuamoa ${ }^{1}$, Nana Afua Kobi Adu-Bobi ${ }^{1}$, \\ Daniel Gyingiri Achel ${ }^{1}$, Isaac Kwabena Asare ${ }^{2}$, Josephine Kyei ${ }^{3}$ \\ ${ }^{1}$ Applied Radiation Biology Centre, Radiological and Medical Sciences Research Institute, Ghana Atomic Energy Commission, Legon, \\ Accra, Ghana \\ ${ }^{2}$ Radiation Technology Centre, Biotechnology and Nuclear Agriculture Research Institute, Ghana Atomic Energy Commission, Legon, Accra, \\ Ghana \\ ${ }^{3}$ V Mane Fils Ghana Limited, East Legon, Accra, Ghana
}

Email address:

shadrachdonkor2000@yahoo.com (S. Donkor)

\section{To cite this article:}

Shadrack Donkor, Akwasi Akomeah Agyekum, Felicia Akuamoa, Nana Afua Kobi Adu-Bobi, Daniel Gyingiri Achel, Isaac Kwabena Asare, Josephine Kyei. Antioxidant Potentials of Tomato Paste Extracts Found on Major Markets in Accra Metropolis. American Journal of Applied Chemistry. Vol. 3, No. 5, 2015, pp. 158-163. doi: 10.11648/j.ajac.20150305.11

\begin{abstract}
The harmful effects of the free radicals on humans could be inhibited by antioxidants in fruits and vegetables. Tomato contains several antioxidants such as phenolic compounds and flavonoids. Consumption of tomatoes has been related epidemiologically to a lower incidence of cardiovascular diseases, prostate, gastrointestinal and epithelial cell cancers. In this study ten different brands of canned tomato pastes on the Ghanaian market were evaluated for their antioxidant potentials based on their polyphenolic and flavonoid contents as well as DPPH free radical scavenging activities. The amount of total phenolic compounds extracted were determined using the Folin-Ciocalteu reagent. Total flavonoid content was determined using aluminum chloride colorimetric assay method. The antioxidant activities were evaluated using the DPPH scavenging activity. Total phenolic and flavonoid contents ranged from $6.26 \mathrm{mg} \mathrm{GAE} / \mathrm{g}_{\mathrm{dw}}$ to $22.82 \mathrm{mg} \mathrm{GAE} / \mathrm{g}_{\mathrm{dw}}$ and between $1.83 \mu \mathrm{g}$ $\mathrm{QE} / \mathrm{g}_{\mathrm{dw}}$ to $45.26 \mu \mathrm{g} \mathrm{QE} / \mathrm{g}_{\mathrm{dw}}$ respectively. DPPH scavenging activity ranged from $8.03 \%$ to $29.69 \%$. High and significant correlations existed between antioxidant activities, total phenolic and flavonoid contents of tomato paste samples analysed indicating these pastes are potentially rich sources of dietary polyphenolic compounds and antioxidants, and might contribute important health benefits to consumers.
\end{abstract}

Keywords: Antioxidant Activity, Total Phenolics, Total Flavonoids, Tomato Pastes, Health Benefits

\section{Introduction}

Tomato (Solanum lycopersicum L.) belongs to the family Solanaceae. It is a horticultural crop of great interest, being widely consumed either fresh or processed such as tomato juice, soup, paste, puree, ketchup, sauce and salsa [1]. Tomato fruits are rich sources of potentially bioactive compounds. Among the most prominent phytochemicals in tomatoes are the carotenoids, of which lycopene is the most abundant in the ripened fruit, accounting for approximately $80-90 \%$ of the total pigments [2]. The lycopene pigment has attracted much interest among researchers because of its biological and physicochemical properties, especially related to its effect as a natural antioxidant and its various benefits for human health [3]. Along with carotenoids, other antioxidant compounds of tomato fruits such as ascorbic acid and phenolics play important and determinant roles in disease prevention. The regular consumption of tomatoes or tomato products has been related epidemiologically to a lower incidence of cardiovascular diseases, prostate, gastrointestinal and epithelial cell cancers through its antioxidant properties [4].

Antioxidants are protective agents that inactivate reactive oxygen species and therefore significantly delay or prevent oxidative damage. They are found in plant materials and supplements. Due to their natural origin, the antioxidants obtained from plants are of greater benefit in comparison to synthetic ones [5]. The use of natural antioxidants from plants does not induce side effects, while synthetic antioxidants were found to have genotoxic effects [6]. 
Antioxidants protect cells from damage caused by unstable molecules known as free radicals. Thus antioxidants are often described as "mopping up" free radicals; meaning they neutralize the electrical charge and prevent the free radicals from taking electrons from other molecules by donating electrons without forming another themselves.

Free radicals are molecules with incomplete electron shells which make them more chemically reactive than those with complete electron shells. They impact negatively on health by promoting the development of cancers, cardiovascular diseases and diabetes. These free radicals are generated during normal body metabolism. Though the human body produces its own antioxidants such as glutathione, ubiquinone (co-enzyme Q), the amounts may be augmented by external sources. Exogenous intake of antioxidants can help the body scavenge free radicals effectively [7]. Current dietary guidelines to combat chronic diseases, including cancer and coronary artery disease, recommend increased intake of plant foods, including fruits and vegetables, which are rich sources of antioxidants. Numerous epidemiological studies have confirmed significant relationship between high intake of flavonoids and decrease in the risk of developing cardiovascular diseases and other degenerative diseases [8,9].

Nowadays, busy lifestyles are driving the development and dependence on convenience foods. Due to busy nature of our lifestyles, most families have less time to cook at home and tend to patronise fast foods to the detriment of their health. Since most homes rely on canned tomato pastes for stew and soup, there is the need to determine the antioxidant properties in them. To our knowledge, there is a dearth of study on the antioxidant activity of tomato pastes on our markets. The basic aim of the research was to evaluate the antioxidant potential of some canned tomato pastes sold on the Ghanaian markets

\section{Materials and Methods}

\subsection{Chemicals}

Folin-Ciocalteu phenol reagent (FCR), Gallic acid, 2, 2-D iphenyl-1-picrylhydrazyl hydrate (DPPH), quercetin and ascorbic acid (vitamin C) were from Sigma Aldrich. $\mathrm{AlCl}_{3}$, $\mathrm{Na}_{2} \mathrm{CO}_{3}, \quad \mathrm{CH}_{3} \mathrm{COOK}$, were from Merck (Darmstadt, Germany). Ethanol and methanol were from Jansen Chimica (Beerse, Belgium). All chemicals were of analytical grade

\subsection{Sample Preparation}

Ten brands of canned tomato pastes were obtained from the Makola, Madina and Kaneshie markets in Accra and were coded GO, OA, TT, SA, SE, AC, ST, FT, LE and FI. The entire content of the tomato pastes were transferred into beakers, frozen and freeze dried (Tokyo Rikakikai Co. Ltd., Tokyo, Japan) Lyophilized samples were pulverized, vacuumised and stored at $4^{\circ} \mathrm{C}$ till required. $0.5 \mathrm{~g}$ of each pulverized sample was extracted in $10 \mathrm{ml}$ of $96 \%$ ethanol. The mixture was placed in a conical flask (wrapped with an aluminum foil) and agitated at $200 \mathrm{rpm}$ with orbital shaker for 1 hour at $25^{\circ} \mathrm{C}$. Additional $10 \mathrm{ml}$ of ethanol was used to re-extract the plant residue and the supernatants pooled. The procedure was repeated using distilled water instead of ethanol as solvent.

\subsection{Determination of Total Phenolic Content}

Determination of total phenolic content was carried out by Folin-Ciocalteu (FC) method using Gallic acid as standard

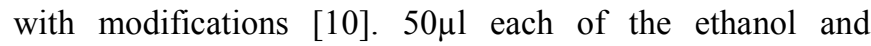
aqueous extracts was mixed with $3 \mathrm{ml}$ of distilled water $\left(\mathrm{dH}_{2} \mathrm{O}\right)$ and $250 \mu \mathrm{l}$ of $\mathrm{FC}$ reagent. The mixture was allowed to stand for 5 minutes, and then $750 \mu \mathrm{l}$ of $20 \% \mathrm{Na}_{2} \mathrm{CO}_{3}$ was added. The resulting mixture was vigorously vortexed for two minutes. After incubation of the resulting reaction mixtures for $30 \mathrm{~min}$ at room temperature absorbance values were measured at $760 \mathrm{~nm}$ using a UV-VIS Spectrophotometer (Shimadzu, 1201, Japan). All determinations were performed in triplicate. A calibration curve was prepared using freshly prepared $1 \mathrm{mg} / \mathrm{mL}$ Gallic acid dissolved in water and serially diluted to the following concentrations, $0.2 \mathrm{mg} / \mathrm{mL}, 0.4$ $\mathrm{mg} / \mathrm{mL}, 0.6 \mathrm{mg} / \mathrm{mL}, 0.8 \mathrm{mg} / \mathrm{mL}$ and $1 \mathrm{mg} / \mathrm{mL}$. A regression equation of $\mathrm{y}=1159 \mathrm{x}+0.0112$ with regression factor $\mathrm{R}^{2}=$ 0.998 was obtained.

The polyphenolic content in each extract was determined from the calibration curve and final results were recalculated and expressed as gallic acid equivalents per gram of dry tomato sample (mg GAE/g $\mathrm{g}_{\mathrm{dw}}$ ).

\subsection{Determination of Total Flavonoid Content}

The aluminum chloride colorimetric assay method [11] was employed to evaluate total flavonoid content (TFC) in the samples using quercetin as standard. An aliquot of $500 \mu 1$ of extracts were mixed with $1500 \mu$ l of $99.9 \%$ ethanol (EtOH), $100 \mu \mathrm{l}$ of $1 \mathrm{M}$ potassium acetate, $100 \mu \mathrm{l}$ of $10 \%$ aluminum chloride and $3000 \mu \mathrm{l}$ of distilled water. The mixture was shaken vigorously and left to stand in the dark at room temperature. The resulting mixtures were incubated for 30 minutes at room temperature and corresponding absorbance measured at $415 \mathrm{~nm}$. All determinations were carried out in triplicate. A standard calibration curve was constructed using quercetin standard solutions of $12.5 \mu \mathrm{g} / \mathrm{ml}, 25 \mu \mathrm{g} / \mathrm{ml}, 50 \mu \mathrm{g} / \mathrm{ml}$, $75 \mu \mathrm{g} / \mathrm{ml}$ and $100 \mu \mathrm{g} / \mathrm{ml} .500 \mu \mathrm{l}$ of each standard was treated in the same manner as the samples above and a calibration linear regression equation $y=0.0105 x+0.0054$ generated. Flavonoid content of each extract was determined from the curve and the final results recalculated and expressed as microgram quercetin equivalent per gram of dry tomato sample $\left(\mu \mathrm{g} \mathrm{QE} / \mathrm{g}_{\mathrm{dw}}\right)$.

\subsection{Determination of Antioxidant Activity}

The free radical scavenging ability of the extracts against DPPH free radical was evaluated as described elsewhere [12], with some modifications. Briefly, $200 \mu$ l of extracts were each added to $3800 \mu$ l of $0.004 \%$ DPPH methanolic solution. After 60 minutes of incubation at room temperature in the dark, the absorbance was measured at $517 \mathrm{~nm}$. A blank 
sample containing only methanol was used to zero the spectrophotometer. Ascorbic acid was used for comparison. Each experiment was performed in triplicate. Antioxidant activity (I \%) was calculated as follows:

$$
\mathrm{I} \%=[(\mathrm{Abs} 0-\mathrm{Abs} 1) / \mathrm{Abs} 0] * 100
$$

$\mathrm{Abs}_{0}=$ absorbance of $0.004 \% \mathrm{DPPH}$ without analyte.

$\mathrm{Abs}_{1}=$ absorbance of $0.004 \%$ DPPH plus the test compound.

\subsection{Data Analysis}

Data were presented as means \pm pooled standard error. Statistical analysis was done using Statgraphics centurion version 16.1. Two-way ANOVA was used to test whether there was a significant difference in total phenolic content, antioxidant activity and scavenging activity between the ethanolic and aqueous extractions. Differences in the active principle contents among the various tomato pastes and extraction methods were estimated with multiple range test using the least significant difference (LSD) test at $\mathrm{p}<0.05$. The data were correlated using Pearson correlation coefficient at $\mathrm{p}<0.05$.

\section{Results and Discussion}

\subsection{Total Phenolic Content}

The concentration of the total phenolic content in the sample of ten tomato pastes examined ranged from 6.26 to $22.82 \mathrm{mg} \mathrm{GAE} / \mathrm{g}_{\mathrm{dw}}$. There was high significant differences ( $\mathrm{p}$ $<0.05)$ in the phenolic content in the different tomato pastes (Table 1). The highest total phenolic content of $22.82 \mathrm{mg}$
$\mathrm{GAE} / \mathrm{g}_{\mathrm{dw}}$ was observed in the aqueous extract of $\mathrm{OA}$ with a corresponding value of $11.69 \mathrm{mg} \mathrm{GAE} / \mathrm{g}_{\mathrm{dw}}$ for its ethanolic extract. This was followed by TT (18.94 mg GAE/g $\left.\mathrm{g}_{\mathrm{dw}}\right), \mathrm{AC}$ (17.00 mg GAE $\left./ \mathrm{g}_{\mathrm{dw}}\right)$, ST (15.32 $\left.\mathrm{mg} \mathrm{GAE} / \mathrm{g}_{\mathrm{dw}}\right)$, GO (15.19 $\left.\mathrm{mg} \mathrm{GAE} / \mathrm{g}_{\mathrm{dw}}\right)$, SA (10. $\left.14 \mathrm{mg} \mathrm{GAE} / \mathrm{g}_{\mathrm{dw}}\right)$, FI (9.62 mg $\left.\mathrm{GAE} / \mathrm{g}_{\mathrm{dw}}\right)$, FT (8.72 $\left.\mathrm{mg} \mathrm{GAE} / \mathrm{g}_{\mathrm{dw}}\right)$, LE $\left(7.17 \mathrm{mg} \mathrm{GAE} / \mathrm{g}_{\mathrm{dw}}\right)$ and $\mathrm{SE}\left(6.91 \mathrm{mg} \mathrm{GAE} / \mathrm{g}_{\mathrm{dw}}\right)$. The corresponding ethanolic extract values were $9.50 \mathrm{mg} \mathrm{GAE} / \mathrm{g}_{\mathrm{dw}}, 8.20 \mathrm{mg} \mathrm{GAE} / \mathrm{g}_{\mathrm{dw}}$, $7.55 \mathrm{mg} \mathrm{GAE} / \mathrm{g}_{\mathrm{dw}}, 7.04 \mathrm{mg} \mathrm{GAE} / \mathrm{g}_{\mathrm{dw}}, 6.26 \mathrm{mg} \mathrm{GAE} / \mathrm{g}_{\mathrm{dw}}$, $6.91 \mathrm{mg} \mathrm{GAE} / \mathrm{g}_{\mathrm{dw}}, 8.85 \mathrm{mg} \mathrm{GAE} / \mathrm{g}_{\mathrm{dw}}, 6.65 \mathrm{mg} \mathrm{GAE} / \mathrm{g}_{\mathrm{dw}}$ and $6.26 \mathrm{mg} \mathrm{GAE} / \mathrm{g}_{\mathrm{dw}}$ respectively.

Relatively high polyphenolic contents were recorded in all the aqueous extracts of the ten tomato pastes used in the study which could be attributed in part to water-soluble pectin contained in tomato pastes [13]. However, our results are not in agreement with results of other work [14] which reported relatively low content of polyphenolic compounds in water extracts as compared to alcoholic extracts. Comparing our data to results reported by other authors [15, 16] in studies of polyphenol content of tomato, wide differences were noted. All the polyphenolic contents of their data far exceeded that from this study. The unit of their measurement was $\mathrm{mg}$ GAE/ $\mathrm{kgfw}$ of extract while our results are expressed in $\mathrm{mg} \mathrm{GAE} / \mathrm{g}_{\mathrm{dw}}$. The reason for this observation may be that while they employed fresh tomato varieties for their extractions, we used processed tomato pastes. It has been proven that mildly processed vegetables possess a significantly lower phenolic content than fresh vegetables [17] and their antioxidant capacity decreases proportionally [18].

Table 1. Total phenolic, total flavonoid contents and DPPH free radical scavenging activities of the various tomato pastes analysed.

\begin{tabular}{|c|c|c|c|c|c|c|}
\hline \multirow{2}{*}{ Sample } & \multicolumn{2}{|c|}{ Total Phenolic Content (mg GAE/g $\mathrm{g}_{\mathrm{dw}}$ ) } & \multicolumn{2}{|c|}{ Total Flavonoid Content $\left.(\mu \mathrm{g} Q E) / g_{d w}\right)$} & \multicolumn{2}{|l|}{ DPPH (\%) } \\
\hline & Aqueous & Ethanol & Aqueous & Ethanol & Aqueous & Ethanol \\
\hline GO & $15.19 \pm 0.26^{\mathrm{d}}{ }_{\mathrm{x}}$ & $7.04 \pm 0.26^{\mathrm{de}}$ & $30.55 \pm 0.36_{x}^{\mathrm{e}}$ & $3.97 \pm 0.36_{y}^{c}$ & $20.21 \pm 0.04_{x}^{e}$ & $9.74 \pm 0.04_{y}^{\mathrm{d}}$ \\
\hline $\mathrm{OA}$ & $22.82 \pm 0.26_{\mathrm{x}}^{\mathrm{a}}$ & $11.69 \pm 0.26^{\mathrm{a}}$ & $45.26 \pm 0.36_{\mathrm{x}}^{\mathrm{a}}$ & $10.12 \pm 0.36_{y}^{\mathrm{a}}$ & $29.69 \pm 0.04_{x}^{a}$ & $14.03 \pm 0.04^{\mathrm{a}} \mathrm{y}$ \\
\hline TT & $18.94 \pm 0.26_{\mathrm{x}}^{\mathrm{b}}$ & $9.50 \pm 0.26_{y}^{b}$ & $43.69 \pm 0.36_{\mathrm{x}}^{\mathrm{b}}$ & $6.55 \pm 0.36^{\mathrm{b}} \mathrm{y}$ & $24.32 \pm 0.04^{b}{ }_{x}$ & $11.43 \pm 0.04_{y}^{b}$ \\
\hline SA & $10.14 \pm 0.26_{\mathrm{x}}^{\mathrm{e}}$ & $6.26 \pm 0.26_{y}^{\mathrm{e}}$ & $29.97 \pm 0.36_{\mathrm{x}}^{\mathrm{e}}$ & $2.83 \pm 0.36_{y}^{\mathrm{d}}$ & $13.88 \pm 0.04^{\mathrm{h}}{ }_{\mathrm{x}}$ & $8.03 \pm 0.04_{y}^{\mathrm{f}}$ \\
\hline SE & $6.91 \pm 0.26_{x}^{g}$ & $6.26 \pm 0.26_{\mathrm{x}}^{\mathrm{e}}$ & $20.69 \pm 0.36^{\mathrm{gh}} \mathrm{x}$ & $1.83 \pm 0.36_{y}^{\mathrm{d}}$ & $11.87 \pm 0.04_{\mathrm{x}}^{\mathrm{j}}$ & $8.74 \pm 0.04_{y}^{\mathrm{e}}$ \\
\hline $\mathrm{AC}$ & $17.00 \pm 0.26_{\mathrm{x}}^{\mathrm{c}}$ & $8.20 \pm 0.26_{y}^{\mathrm{c}}$ & $35.40 \pm 0.36_{\mathrm{x}}^{\mathrm{c}}$ & $5.54 \pm 0.36^{\mathrm{bc}} \mathrm{y}$ & $23.12 \pm 0.04^{\mathrm{c}}{ }_{\mathrm{x}}$ & $11.15 \pm 0.04^{\mathrm{c}}$ \\
\hline FT & $8.72 \pm 0.26_{\mathrm{x}}^{\mathrm{f}}$ & $8.85 \pm 0.26^{\mathrm{bc}}{ }_{\mathrm{x}}$ & $19.97 \pm 0.36_{x}^{\mathrm{h}}$ & $3.40 \pm 0.36_{y}^{\mathrm{c}}$ & $14.39 \pm 0.04_{x}^{f}$ & $9.74 \pm 0.04_{y}^{d}$ \\
\hline LE & $7.17 \pm 0.26^{g}$ & $6.65 \pm 0.26_{\mathrm{x}}^{\mathrm{e}}$ & $23.69 \pm 0.36_{x}^{f}$ & $4.26 \pm 0.36^{\mathrm{c}} \mathrm{y}$ & $12.75 \pm 0.04_{\mathrm{x}}^{\mathrm{i}}$ & $8.75 \pm 0.04_{\mathrm{y}}^{\mathrm{e}}$ \\
\hline FI & $9.62 \pm 0.26^{\mathrm{e}}$ & $6.91 \pm 0.26^{\mathrm{de}}$ & $21.69 \pm 0.36_{x}^{g}$ & $4.97 \pm 0.36_{y}^{c}$ & $14.24 \pm 0.04_{\mathrm{x}}^{\mathrm{g}}$ & $8.62 \pm 0.04_{\mathrm{y}}^{\mathrm{e}}$ \\
\hline & $\mathrm{LSD}=0.7838$ & & $\mathrm{LSD}=1.06$ & & $\mathrm{LSD}=0.131$ & \\
\hline
\end{tabular}

Means \pm Pooled standard error from three replicates; ${ }^{\mathrm{a}-\mathrm{j}}$ different superscript alphabet in the same column are significantly different $\mathrm{P} \leq 0.05$; ${ }^{\mathrm{x}-\mathrm{y}}$ different subscript alphabet on the same row are significantly different $\mathrm{P} \leq 0.05$.

Polyphenolic compounds are known as important plant constituents due to their scavenging ability provided by the hydroxyl groups. In addition phenolic compounds were reported to be associated with antioxidant activity and play important roles in the stabilizing of lipid peroxidation [19]. Natural phenolics are able to provide antioxidative function through various ways, such as intercepting singlet oxygen, decomposing primary products of oxidation, preventing continued hydrogen abstraction from substances, etc.
Numerous studies have shown that consumption of foods high in phenolic content can reduce the risk of heart disease by slowing the progression of atherosclerosis, because they act as antioxidants [20, 21] Therefore, tomato may have potential as a reservoir of natural antioxidants in food.

\subsection{Total Flavonoid Content}

In Table 1, the total flavonoid contents are shown. The aqueous extracts yielded higher values compared to their 
ethanolic counterparts. The highest total flavonoid content for aqueous extract was recorded in OA with value of 45.26 $\mu \mathrm{g} \mathrm{QE} / \mathrm{g}_{\mathrm{dw}}$ followed by TT $43.69 \mu \mathrm{g} \mathrm{QE} / \mathrm{g}_{\mathrm{dw}}, \mathrm{AC} 35.40 \mu \mathrm{g}$ $\mathrm{QE} / \mathrm{g}_{\mathrm{dw}}$. The aqueous extracts of $\mathrm{ST}, \mathrm{GO}$ and $\mathrm{SA}$ yielded values of $35.40 \mu \mathrm{g} \mathrm{QE} / \mathrm{g}_{\mathrm{dw}}, 32.26 \mu \mathrm{g} \mathrm{QE} / \mathrm{g}_{\mathrm{dw}}, 30.55 \mu \mathrm{g}$ $\mathrm{QE} / \mathrm{g}_{\mathrm{dw}}$ and $29.97 \mu \mathrm{g} \mathrm{QE} / \mathrm{g}_{\mathrm{dw}}$ respectively. The lowest aqueous total flavonoid content values of $23.69 \mu \mathrm{g} \mathrm{QE} / \mathrm{g}_{\mathrm{dw}}$, $21.69 \mu \mathrm{g} \mathrm{QE} / \mathrm{g}_{\mathrm{dw}}, 20.69 \mu \mathrm{g} \mathrm{QE} / \mathrm{g}_{\mathrm{dw}}$, and $19.96 \mu \mathrm{g} \mathrm{QE} / \mathrm{g}_{\mathrm{dw}}$ were recorded in LE, FI, SE and FT respectively. Based on aqueous total flavonoid content, the tomato pastes available on our local markets can be classified into three groups, those exhibiting relatively high values, ones with low levels and the rest in between the two groups. The tomato pastes having relatively high concentrations of total flavonoid were OA and TT, those in the middle group were AC, ST, GO and SA whereas LE, FI, SE and FT lie within the low levels. Of all the ethanolic extracts, OA showed highest total flavonoid concentration of $10.12 \mu \mathrm{g} \mathrm{QE} / \mathrm{g}_{\mathrm{dw}}$ which is four times lower than its aqueous counterpart. TT, ST, AC, FI, LE, GO, FT and SA furnished ethanolic total flavonoid values of $6.55 \mu \mathrm{g}$ $\mathrm{QE} / \mathrm{g}_{\mathrm{dw}}, 5.97 \mu \mathrm{g} \mathrm{QE} / \mathrm{g}_{\mathrm{dw}}, 5.54 \mu \mathrm{g} \mathrm{QE} / \mathrm{g}_{\mathrm{dw}}, 4.97 \mu \mathrm{g} \mathrm{QE} / \mathrm{g}_{\mathrm{dw}}$, $4.26 \mu \mathrm{g} \mathrm{QE} / \mathrm{g}_{\mathrm{dw}}, 3.97 \mu \mathrm{g} \mathrm{QE} / \mathrm{g}_{\mathrm{dw}}, 3.40 \mu \mathrm{g} \mathrm{QE} / \mathrm{g}_{\mathrm{dw}}$ and $2.83 \mu \mathrm{g}$ $\mathrm{QE} / \mathrm{g}_{\mathrm{dw}}$ respectively. The ethanolic extract of $\mathrm{SE}$ furnished the lowest value of $1.83 \mu \mathrm{g} \mathrm{QE} / \mathrm{g}_{\mathrm{dw}}$. This is not in agreement with results of previous work $[16,22]$ where higher levels of total flavonoid content were recorded. Data from this study showed that total flavonoid values of aqueous extracts were exceedingly greater than their ethanolic counterpart which is not consistent with earlier report [23]. The presence of a number of hydroxyl groups in polyphenols (e.g. flavonoids especially the glycosides) make them more hydrophilic and generally more soluble in water than ethanol [24] and could partly be responsible for the high differences in our results.

Among the phenolic compounds are flavonoids which possess biological activities such as antioxidative, antiinflammatory and antiatherosclerotic activities. The antioxidative properties of flavonoids can be linked to several different mechanisms, such as scavenging of free radicals, chelation of metal ions, such as iron and copper, and inhibition of enzymes responsible for free radical generation. The many pharmacological effects of phenolic compounds and flavonoids are linked to their ability to act as strong antioxidants and free radical scavengers, to chelate metals, and to interact with enzymes, adenosine receptors, and biomembranes [25].

\subsection{DPPH Free Radical Scavenging Assay}

Free radical scavenging is one of the known mechanisms by which antioxidants inhibit lipid oxidation. Antioxidant capacity is clearly associated with the activity of "free radical scavenging enzymes" (superoxide dismutase, catalase, peroxidase, etc.) and with the contents of antioxidant substances, mainly phenolic compounds, carotenoids, tocopherol and ascorbic acid. When a comparison was made between two different extraction methods (Table 1) aqueous extracts had a significantly higher DPPH free radical scavenging activity than ethanol extracts. With regards to the aqueous extract, the free radical scavenging activity ranged from $11.87 \%$ - $29.69 \%$ whereas free radical scavenging activity of the ethanolic extract ranged from $8.03 \%-14.03 \%$. The highest scavenging activity of the aqueous extract of $29.69 \%$ was registered for OA whilst the lowest ethanolic extract of $8.03 \%$ was seen in SA. The ethanolic extracts of OA, TT, AC, ST, FT, GO, LE, SE and FI had scavenging activities of $14.03 \%, 11.43 \%, 11.15 \%, 11.06 \%, 9.74 \%$, $9.74 \%, 8.75 \%, 8.74 \%$, and $8.62 \%$ respectively. The total antioxidant activities obtained in this study were comparable with other research [26] but higher than that of similar work done earlier [22]. This could be due to the medium of extraction. Antioxidant activity of extracts is strongly dependent on the types of solvent used as compounds with different polarity exhibiting differing rates of antioxidant potential [27].

\subsection{Relationships Between Total Phenolic and Total Flavonoid and Antioxidant Activity}

A Pearson correlation was done to ascertain the relationships between the individual parameters evaluated and to establish their relative importance in determining antioxidant activity. There was a very strong linear correlation $(\mathrm{r}=0.9755)$ between the total phenolic content and the scavenging of DPPH radical activity (Table 2). This was in agreement with similar report done by others [28]. These results indicated that the radical scavenging capacity of extract might be mostly related to their concentration of phenolic hydroxyl group. The antiradical activity of phenolic compounds depends on their molecular structure, availability of phenolic hydrogens and possibility for stabilization of the resulting phenoxyl radicals formed by hydrogen donation [29]. A significant and positive high Pearson's correlation ( $r$ $=0.9235$ ) was observed between total flavonoid and DPPH free radical scavenging activity as shown in Table 2 . This is in contrast with work done on vegetables [30] which indicates that flavonoids did not contribute to antioxidant activity of vegetables. Flavonoids which belong to the phenolic compounds, strongly correlated $(r=0.8518)$ with phenolic content of the tomato pastes analysed (Table 2) which was not consistent with data from Nigeria [22]. Flavonoids are phenolic compounds which possess biological activities such as anti-inflammatory, anti-carcinogenic and anti-atherosclerotic activities.

Table 2. Correlation between total phenolic, total flavonoid contents and antioxidant activity.

\begin{tabular}{llll}
\hline Main Effect & Total Phenolics & Total Flavonoids & DPPH \\
\hline Total Phenolics & - & & \\
Total Flavonoids & $0.8518^{*}$ & - & \\
DPPH & $0.9755^{*}$ & $0.9235^{*}$ & - \\
Scavenging & & & \\
\hline
\end{tabular}

*means highly significant

\section{Conclusion}

Current dietary guidelines to combat chronic diseases, 
including cancer and coronary artery diseases recommend increased intake of plant foods, including fruits and vegetables, which are rich sources of antioxidants. Tomato which is widely consumed as either fresh or processed food plays an important role in human diet. We have demonstrated that extracts of some brands of tomato paste sold on the Ghanaian markets contain significant amounts of polyphenolic and flavonoid compounds capable of quenching $\mathrm{DPPH}^{*}$ free radicals. According to this study, a significant and linear relationship was found between the antioxidant activity and the total phenolic and flavonoid contents indicating that polyphenolic compounds contribute significantly to antioxidant activity of the investigated tomato pastes and can therefore be considered as good natural antioxidants source with numerous health benefits assuming that these compounds are bioavailable when consumed.

\section{Acknowledgement}

The authors would like to appreciate the assistance of laboratory staff from Nuclear Chemistry and Environmental Research Centre, NNRI, GAEC throughout this work.

\section{References}

[1] Ray, R.C.. El Sheikha, A.F., Panda, S.H. and Montet, D. (2011) Anti-oxidant properties and other functional attributes of tomato. An overview Int. J. Fd. Ferm. Technol., 1, (2), 139-148.

[2] Helyes, L.A., Lugasi, A. Pogonyi, C. and Pék, Z. (2009) Effect of variety and grafting on lycopene content of tomato (Lycopersicon Lycopersicum L. Karsten) fruit. Acta Aliment Hung., 38, (1), 27-34.

[3] Hernández, M. E. Rodríguez, E. and Díaz, C. (2007) Free hydroxycinnamic acids, lycopene, and color parameters in tomato cultivars. J Agric Food Chem., 55, 8604-8615.

[4] Rao, A.V. and Rao, L.G. (2007) Carotenoids and human health: Pharm. Res. 55, (3), 207-216.

[5] Rohman, A., Riyanto, S., Yuniart, I.N., Saputra, W.R. and Utam, I.R. (2010) Antioxidant activity, total phenolic, and total flavonoid of extracts and fractions of red fruit (Pandanus conoideus Lam). Int. Food Res. J., 17, 97-106.

[6] Chen, C., Pearson, M.A. and Gray, I.J. (1992) Effects of synthetic antioxidants (BHA, BHT and PG) on the mutagenicity of IQ-like compound. Food Chem., 43, 177-183.

[7] Valko, M., Leibfritz, D., Monco, I.J., Cronin, M. and J. Telser J. (2007) Free radicals and antioxidants in normal physiological functions and human disease. Int. J of Biochem \& Cell Biol., 39, (1), 44-84.

[8] Heiss, C.L.,. Keen, M. and Kelm, R. (2010) Flavanols and cardiovascular disease prevention. Eur Heart J., 31, 2583-92.

[9] Williamson, G.H., Sies, D., Heber, C.L., Keen, I.A.. Macdonald, L., Actis-Goretta, T.Y., Momma, J.I.,.Ottaviani, R.R, Holt, H.,. Schroeter, C. and Heiss, C. (2009) Functional foods for health promotion: state-of-the-science on dietary flavonoids. Nutr. Rev., 67, 736-43.
[10] Singleton, V.L., Orthofer, R., Lamuela-Raventós, R.M. and Lester, P. (1999) Methods in Enzymology. Academic Press, pp.152-178.

[11] Zhishen, J., Mengcheng T. and Jianming, W. (1999) The determination of flavonoid contents in mulberry and their scavenging effects on superoxide radicals. Food Chem., 64, $555-559$

[12] Oliveira, I., Sousa, A., Ferreira, I., Bento, A.,. Estevinho, L. and Pereira, J.A. (2008) Total phenols, antioxidant potential and antimicrobial activity of walnut (Juglans regia L.) green husk, Food Chem. Toxicol., 46, 2326-2331.

[13] Hurtado, M.C., Greve L.C. and Labavitch, J.M. (2002) Changes in cell wall pectin accompanying tomato (Lycopersicon esculentum) paste manufacture. J. Agric. Food Chem., 50, 273-278.

[14] Lapornik, M., Prosek, A. and Golc Wondra, A. (2005) Comparison of extracts prepared from plants by-products using different solvents and extraction time. J of Food Eng., 71, 214-222.

[15] Nour, V., Trandafir, I. and Ionica, M.E. (2013) Antioxidant Compounds, Mineral Content and Antioxidant Activity of Several Tomato Cultivars Grown in Southwestern Romania. Not Bot Horti Agrobo., 41, (1), 136-142.

[16] Ilahy, R., Hdiderb, C., Lenuccic, M.S., Tlilia I. and Dalessandroc G., (2011) Phytochemical composition and antioxidant activity of high-lycopene tomato (Solanum lycopersicum L.) cultivars grown in Southern Italy. Sci Horticult., 127, 255-261.

[17] Kalt, W., Forney, C.F., Martin A. and Prior, R.L. (1999) Antioxidant capacity, vitamin $\mathrm{C}$, phenolics, and anthocyanins after fresh storage of small fruits, J Agric Food Chem., 47, $4638-4644$.

[18] Ninfali, P. and Bacchiocca, M. (2004). Parameters for the detection of post-harvest quality in fresh or transformed horticultural crops. J. Food Agric. Environ., 2, 122 -127.

[19] Yen, G.C., Duh, P.D. and Tsai, C.L. 1993. Relationship between antioxidant activity and maturity of peanut hulls. J. Agric. Food Chem. 41, 67-70.

[20] Kahkonen, M.P., Hopia, A.I., Vuorela, H.J., Raucha, J.P. and Pihlaja, K. (1999) Antioxidant activity of plant extracts containing phenolic compounds. J Agric Food Chem., 47, 3954-3962.

[21] Kaur, C. and Kapoor, H.C. (2002). Anti-oxidant activity and total phenolic content of some Asian vegetables. Int J. Food Sci. Technol., 37, 153-161.

[22] Olajire, A.A. and Azeez, L. (2011) Total antioxidant activity, phenolic, flavonoid and ascorbic acid contents of Nigerian vegetables. Afr J of Food Sci Technol., 2, (2), 022-029.

[23] Yeh, J.Y., Hsieh, L.H., Wu K.T. and Tsai, C.F. (2011) Antioxidant properties and antioxidant compounds of various extracts from the edible Basidiomycete grifola Frondosa (Maitake). Molecules, 16, (4) 3197-3211.

[24] Escribano-Bailon, M.T. and Santos-Buelga, C. (2003) In Methods in Polyphenol Analysis. Royal Society of Chemistry, Cambridge, United Kingdom, 1-16. 
[25] Mitra, K. and Uddin, N. (2014) Total Phenolics, Flavonoids, Proanthrocyanidins, Ascorbic Acid Contents and In-Vitro Antioxidant Activities of Newly Developed Isolated Soya Protein. Disc J of Agric Food Sci., 2, (5), 160 -168.

[26] Mostapha, B.B., Hayette L. and Zina, M. (2014) Antioxidant activity of eight tomato (Lycopersicon esculentum L.) varieties grown in Algeria. J of Food Technol Res., 1 (3), 133145.

[27] Marinova, E.M. and Yanishlieva, N.V. (1997), Antioxidative activity of extracts from selected species of the family Lamiaceae in sunflower oil, Food Chem 58, 245-248.
[28] Kim, J.H., Kim, S.J.. Park, H.R., Choi, J., Cheoul, J.Y., Chang, N.K., Kim S.J. and. Lee, S.C. (2009) The different antioxidant and anticancer activities depending on the colour of oyster mushroom. J. Med. Plants Res., 3, 1016-1020.

[29] Ramarathnam, N., Ochi H. and Takeuchi, M. (1997) Antioxidant defense system in vegetable extracts (F. Shahidi, Edition). AOCS Press, $76-87$.

[30] Nickavar B, Kamalinejad, M. and Izadpanah, H. (2007) In vitro free radical scavenging activity of five salvia species. Pak. J. Pharm. Sci., 20, 291-294. 